\title{
Anterior Surgery of Hard and Soft Cervical Disc
}

\author{
MOHAMED SHABAN, M.D. \\ The Department of Neurosurgery, Faculty of Medicine, Beni Sueif University, Beni Sueif, Egypt
}

\begin{abstract}
Background: Anterior access cervical surgery aims to remove the compressing agent which might be soft disc material or bony spur this offender material is the cause of patient complaint which might be electrical like pain or, numbness in one upper limb or both.
\end{abstract}

Anterior cervical surgery of hard \& soft disc aims towards the excision of the bony osteophyte or disc material that is compressing the nerve root causing "electrical," "numbness," or "shooting" pain, that often begins in the neck \& travels into one or both shoulders and arms.

Aim of Study: To compare the results of ACDF using cages for interbody fusion in both soft and hard cervical discs extractions regarding the difference in surgical time, loss of blood, post-operative hospital stay, relief of presenting symptoms, the incidence of complications \& return to regular work.

Patients and Methods: This is a, retrospective. Study of 21 patients with the diagnosis of cervical disc prolapse operated upon by ACDF with cages instrumentation in the period from $5 / 2012-5 / 2015$ in the Department of Neurosurgery, Beni Sueif University.

Cases were divided, into 2 groups:

- Group A: 14 patients with (single/double) levels soft cervical discs.

- Group B: 7 patients with (single/double) levels hard cervical discs.

Results: 21 cases were included in this series. The mean age was 35 in group (A) and 49 in group (B), there were six females, and 15 were males. 14 patients had single level discs, and seven patients had two levels.

Operative time was to some extent longer in hard disc cases than soft disc cases. Also, blood loss was somewhat more in hard disc than soft disc patient satisfaction is equal in the two groups; but return to regular work was after eight weeks in the hard disc in comparison to 6 weeks in soft disc period of follow-up was six month of both groups showing no difference in the outcome.

Conclusion: Although ACDF for hard cervical discs requires longer, operative time and may cause more loss of

Correspondence to: Dr. Mohamed Shaban, The Department of Neurosurgery, Faculty of Medicine, Beni Sueif University, Beni Sueif, Egypt blood \& more delayed return to regular work when compared to the soft discs, the clinical outcome during six months follow-up period showed no difference between the 2 groups.

Key Words: Anterior surgery - Hard and soft cervical disc.

\section{Introduction}

THE pathophysiology of cervical nerve root compression, may happen through one of two mechanisms.

First, nuclear material arising from acute soft disk herniations may impinge on the exiting nerve root posterolaterally at its take-off from the cervical cord or intraforaminally as it traverses the neuroforamen [1-4]

Second, chronic disk degeneration with resultant disk height loss may result in so-called hard disk pathology, caused by annular bulging without frank herniation or by the formation of degenerative osteophytes, which typically arise from the uncinate regions of the posterolateral vertebral body [5-8] .

It can be challenging to distinguish between soft $\&$ hard disk pathology relying on the use of Magnetic Resonance Imaging (MRI) alone. So cervical X-ray and a noncontrast computed tomography scan can be used to complement information obtained on MRI [9-12]

Aim of the study:

To compare the results of ACDF using cages for interbody fusion in soft and hard cervical discs regarding surgical time, loss of blood, postoperative hospital stay, relief of presenting symptoms, the incidence of complications \& return to regular work.

\section{Patients and Methods}

A retrospective, study on 21 cervical patients with the diagnosis of disc prolapse operated upon 
by ACDF plus cages in the period from 1/2012$5 / 2015$ in the Department of Neurosurgery, Beni Sueif University.

Cases were divided into 2 groups:

- Group A: 14 patients with single/double levels soft cervical discs.

- Group B: 7 patients with single/double levels hard cervical discs.

\section{Inclusion criteria:}

- Symptoms of cervical disc pathology in the form of neck pain, cervical radiculopathy and/or myelopathy.

- Radiographically determined discogenic origin to include at least one of the following:

A- Decreased disc height compared to adjacent levels on radiogram film or MRI.

B- Disc herniation on MRI.

C- Failure of conservative medical treatment.

- Willing and able to comply with the post-operative management program.

\section{Exclusion criteria:}

- Non-discogenic source of symptoms, e.g., tumor.

- Lesions extending posterior to the body of the vertebra in which corpectomy is the preferred option for anterior decompression.

- Multiple levels disc herniation.

- Patients not fit for general anesthesia.

- Improvement of symptoms with medical treatment and/or physiotherapy.

Patients were subjected to:

- History taking.

- General and neurological examination focusing on motor and sensory examination.

- Investigations: Pre-operative MRI cervical spine (T1 and T2 images, axial and sagittal views), plain Cervical spine X-rays (A.P. view, lateral view in the neutral position and lateral views in flexion and extension) \pm Cervical Spine CT.

Post-operative plain radiographs 1-2 days after the operation, then at 3 and 6 months in follow-up period.

\section{Operative procedure:}

All patients were operated upon lying supine under general anesthesia, with the patient's head in mild extension on a horseshoe with a rolled towel between the patient's shoulders. The shoulders were taped gently to the operative table to facilitate imaging down to the $\mathrm{C} 7-\mathrm{T} 1$ region.

The elbows were padded to avoid compression. A right-sided approach was performed via a transverse or longitudinal skin opening. Then there was undermining of the platysma for the provision of tissue relaxation \& also to prevent tissue injury due to retraction. Blunt surgical dissection is used to open surgical planes downwards exposing the anterior aspects of the cervical vertebrae.

The prevertebral fascia $\&$ longus coli's medial borders were divided using electrocautery.

Intraoperative image guidance was used to confirm the operative levels. Lateral retraction blades are placed bilaterally under the medial dissected edges of the longus coli muscles. Casper retractor pins are set in the vertebral bodies above $\&$ below the disc space to be treated.

With the aid of the operating microscope, reaming of adjacent vertebral bodies, appropriate discectomy, removal of the PLL-posterior longitudinal ligament (not routinely indicated but can be carried on if the adequacy of the decompression is in question, or there is a concern of an extruded disc fragment through the ligament) and drilling of the osteophyte (using high speed drill) were performed to provide decompression for the cervical cord, and nerve root in cases of hard cervical disc.

Based on the discectomy's defect size, an appropriate sized cervical cage was inserted. The used cage was prefilled utilizing a mixture of bony shavings harvested from the vertebrae and bone graft substitute. In case of multiple levels, we start with the most compressive level and then sequentially move to the following level and complete the process here as well. Proper hemostasis and closure in layers follow this.

\section{Results}

21 patients were included in the study. The mean age was 35 in group (A) and 49 in group (B), 6 of them were female and 15 were male. 14 patient had single level discs and 7 patients had two levels.

Table (1): Age and sex ratio in both groups.

\begin{tabular}{lcc}
\hline & Group A & Group B \\
\hline Mean of age & 35 & 49 \\
Sex (male/female) & $10 / 4$ & $5 / 2$ \\
\hline
\end{tabular}


Table (2): Number of affected levels in both groups.

\begin{tabular}{ccc}
\hline & Group A & Group B \\
\hline Single level & 10 & 4 \\
Two levels & 4 & 3 \\
\hline & & \\
Table (3): Levels of disc herniation in both groups. \\
\hline \multicolumn{4}{c}{ Group A } & Group B \\
\hline C4-5 & 0 & 2 \\
C5-6 & 7 & 3 \\
C6-7 & 7 & 2 \\
\hline
\end{tabular}

Table (4): Symptoms in both groups.

\begin{tabular}{lcc}
\hline & Group A & Group B \\
\hline Radiculopathy & 10 & 1 \\
Myelopathy & 3 & 5 \\
Myelo-radiculopathy & 1 & 1 \\
\hline
\end{tabular}

Table (5): Result of surgery in both groups.

\begin{tabular}{lll}
\hline & Group A & Group B \\
\hline Neck pain: & & \\
$\quad$ Improved & $12(70.6 \%)$ & $6(64.3 \%)$ \\
$\quad$ Persisted & $2(29.4 \%)$ & $1(35.7 \%)$ \\
Brachialgia: & & \\
$\quad$ Improved & $13(93.3 \%)$ & $6(83.3 \%)$ \\
Persisted & $1(6.7 \%)$ & $1(16.7 \%)$ \\
VAS): Visual Analog Scale: & & \\
Pre-operative & $7.9 \pm 1.1$ & $7.2 \pm 1.8$ \\
Post-operative & $2.5 \pm 1.5$ & $3.1 \pm 1.1$ \\
Motor deficit: & & \\
Unchanged & $3(31.2 \%)$ & $1(27.3 \%)$ \\
Deteriorated & $1(6.3 \%)$ & $1(18.2 \%)$ \\
Numbness: & & \\
Improved & & $5(71.4 \%)$ \\
Not improved & $9(72.7 \%)$ & $2(28.6 \%)$ \\
Patient satisfaction: & $5(27.3 \%)$ & \\
Excellent & & $3(42.8 \%)$ \\
Good & $7(50 \%)$ & 0 \\
Fair & $6(42.8 \%)$ & $3(42.8 \%)$ \\
Poor & $1(7.2 \%)$ & $1(14.4 \%)$ \\
\hline$\quad$ Fishersexact & 0 & \\
\hline
\end{tabular}

Fisher's exact test statical value, one the results of patient satisfaction was not significant as $p$ lower than. 0.5 . Before operation $\&$ at every follow-up, both neck pain and shoulder (ridiculer) pains were evaluated with (VAS) with words as "no pain" at one end and "worst pain" at the other end.

The clinical outcome of the patient graded by Odom's criteria as excellent, then good, then fair or poor.
Table (6): Odom's criteria.

\begin{tabular}{ll}
\hline Excellent & $\begin{array}{l}\text { - All pre-operative symptoms relieved, abnormal } \\
\text { findings improved. }\end{array}$ \\
Good & $\begin{array}{l}\text { - Minimal persistence of pre-operative symptoms, } \\
\text { abnormal findings unchanged or improved. }\end{array}$ \\
Fair & $\begin{array}{l}\text { - Definite relief of some pre-operative symptoms, } \\
\text { other symptoms unchanged or slightly } \\
\text { improved. }\end{array}$ \\
Poor & \begin{tabular}{l} 
- Symptoms and signs unchanged or exacerbated. \\
\hline
\end{tabular}
\end{tabular}

Table (7): Complication in both groups.

\begin{tabular}{|c|c|c|c|c|}
\hline \multirow{2}{*}{ Complication } & \multicolumn{2}{|c|}{ Group A } & \multicolumn{2}{|c|}{ Group B } \\
\hline & No. & $\%$ & No. & $\%$ \\
\hline Transient dysphagia & 1 & 7.5 & 2 & 28.8 \\
\hline Transient hoarseness & 1 & 7.5 & 2 & 28.8 \\
\hline Infection & 0 & & 0 & \\
\hline Hematoma & 0 & & 0 & \\
\hline Dural tear & 0 & & 0 & \\
\hline Spinal cord injury & 0 & & 0 & \\
\hline Cage subsidence & 0 & & 0 & \\
\hline Pseudoarthrosis & 0 & & 0 & \\
\hline \multirow{2}{*}{\multicolumn{5}{|c|}{$\begin{array}{l}\text { - Fisher the fisher exact test statically value is } 0.2474 \text { the result of } \\
\text { Transient. } \\
\text { - Transient hoarsenes and/dysphagia not significant as } p \text { lower than } \\
.05 \text {. }\end{array}$}} \\
\hline & & & & \\
\hline \multicolumn{5}{|c|}{ Table (8): Post-operative hospital stay. } \\
\hline Group A & \multicolumn{4}{|c|}{ Group B } \\
\hline $3 \pm 1$ days & \multicolumn{4}{|c|}{$4 \pm 1$ days } \\
\hline
\end{tabular}

Table (9): Average operative time: Table (5).

\begin{tabular}{lcc} 
& Group A & Group B \\
\hline Single level & 100 minutes & 140 minutes \\
Two levels & 140 minutes & 220 minutes \\
\hline
\end{tabular}

Table (10): A verage blood loss.

\begin{tabular}{ccc}
\hline & Group A & Group B \\
\hline $\begin{array}{c}\text { Single level } \\
\text { Two levels }\end{array}$ & $50 \mathrm{~cm}^{3}$ & $80 \mathrm{~cm}^{3}$ \\
\hline & $90 \mathrm{~cm}^{3}$ & $110 \mathrm{~cm}^{3}$ \\
Table (11): Return to work. & \\
\hline \multicolumn{2}{l}{ Group A } & Group B \\
\hline 6 weeks & 8 weeks \\
\hline
\end{tabular}

Both groups underwent post-operative clinical follow-up for average 6 months; results were evaluated according to patient satisfaction, Fisher's exact probability statistical test was utilized to compare patient satisfaction in the 2 , groups. 
We recorded fusion rates, post-operative complications \& patient satisfaction using Visual An-

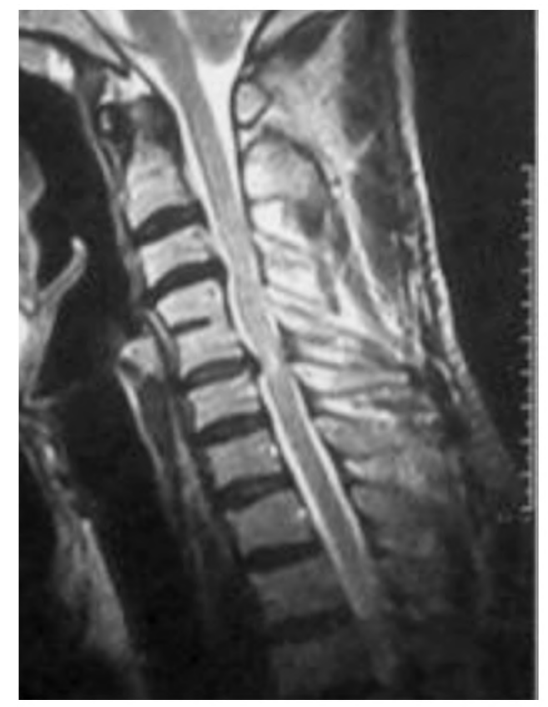

(A) alogue Score (VAS). which show no, difference between these 2 , groups.

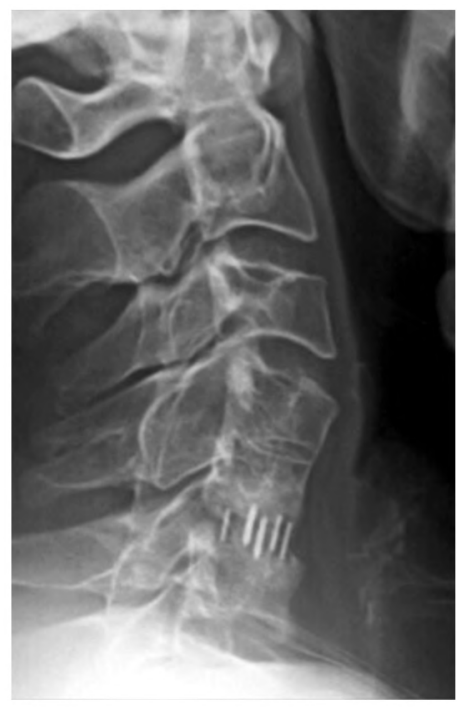

(B)

Fig. (1): (A) MRI sagetal view C5-6 disc (B) cervical X-ray post-operative lat. View show C5-6 cage.

\section{Discussion}

Since the establishment of the anterior cervical microsurgical approach as the preferred procedure for the treatment of anterior disc herniation and spondylotic myelopathy, this anterior cervical discectomy aims towards the excision of the culprit lateral disc fragment or osteophyte.

The procedure also includes replacing the disc with cages with bone granules to maintain disc height, restoring the height of the foramen, maintenance of cervical lordosis and even adjuvant fusion [3,13-15]

In our study hard disc more common in mal especially old age than the soft disc in which occurrence more common in a younger age which the same result obtained by Dade et al., [5] .

The C5-6 disc is the most affected levels followed by C6-7 in the 2, groups.

Average operative time slightly higher by 40 minutes in hard disc than soft disc which also occurs regarding loose blood witch somewhat high by $30 \mathrm{~cm}^{3}$.

The clinical results of both groups reported regarding (VAS) pre-operative 7.9 in the soft disc and 7.2 in the hard disc and post-operative 2.5 in the soft disc and 3.1 in the hard disc.

Regarding patient satisfaction, excellent outcome $50 \%$ in the soft disc and $42.8 \%$ in the hard disc, good outcome $42.8 \%$ in the soft disc and hard disc, fair outcome $7.2 \%$ in the soft disc and 14.4 $\%$ in the hard disc.

In a small randomized trial performed in 21 patients with cervical disc prolapse with failed medical treatment and patient for need for surgery during pre-operative preparation cervical spine $\mathrm{X}$ rays films were done in all patient in which standard soft disc cases, but in hard disc cases foraminal spurs or osteophytes were seen, narrow cervical interspaces were noted in approximately all cases [16-19]

CT cervical spine more accuracy in differentiated hard from the soft cervical disc, but MRI on its own didn't prove to be efficient in the differentiation between hard \& soft disc which the same result obtained by Sengupta D K and his college [18]. The intraobserver observation was satisfactory (ossified) plus radiological outcome for establishing the diagnosis of the presence, or absence of hard disc these result also obtain by. Sengupta DK and his college [18] .

Our result entirely agrees with the results of Dade et al., [5].

As there was no difference between these 2, groups regarding patient satisfaction.

Clinical outcome postoperative complication also the same result obtained by Kadaka et al., [9] but there is a limited number of papers in general 
by review of literature in which comparisons between the result of hard \& soft discs.

Operative morbidity (transient dysphagia and transient hoarseness) was slightly higher in hard disc cases (28.6) than soft disc cases (7,5\%), but both groups improved entirely postoperative after one week, in this series is lower than the $51 \%$ complication rate reported by Connolly et al., [2]

Return to work six weeks in the soft disc and eight weeks in the hard disc with no deficit in the 2 , groups also follow-up period for six months obtain same result both groups.

These results led to a clinical recommendation for hard disc surgery by an anterior approach using careful and meticulous microscopic technique plus drilling of ossified which give the same effect as soft disc surgery.

\section{Conclusion:}

Although ACDF for hard cervical discs requires longer operative time, more loss of blood \& more delayed return to regular work when compared with soft discs, the clinical outcome, \& rate of complications at six months follow-up wasn't statistically.

\section{References}

1- BARON E.M. and YOUNG W.F.: Cervical spondylotic myelopathy: A brief review of its pathophysiology, clinical course, and diagnosis. Neurosurgery, 60: (1 (Supp1) 1S35S41, 2007.

2- CONNOLLY E.S., SEYMOUR R.J. and ADAMS J.E.: Clinical evaluation of anterior cervical fusion for degenerative cervical disc disease. J. Neurosurg., 23: 431-7, 1965.

3- CHANG V. and HOLLY L.T.: Controversies in the management of cervical spondylotic myelopathy. J. Neurosurg. Sci., 57: 241-52, 2013.

4- CHIEN L.C., WU J.C., CHEN Y.C., LIU L., HUANG W.C., CHEN T.J., et al.: Age, sex, and socio-economic status affect the incidence of pediatric spinal cord injury: An eleven-year national cohort study. PLoS One, 7: e39264, 2012.

5- DADE L., DAVID J. BISSONNETTE, PETER J. SHEPTAK and DAVID S.: Anterior surgery for cervical disc disease, Part 1: Treatment of lateral cervical disc herniation in 253 cases J. Neurosurg., 53: 1-11, 1980.

6- EDWARDS C.C. II, RIEW K.D., ANDERSON P.A., HILIBRAND A.S. and VACCARO A.F.: Cervical myelopathy: Current diagnostic and treatment strategies. Spine J., 3: 68-81, 2003.
7- GHOGAWALA Z., BENZEL E.C., HEARY R.F., RIEW K.D., ALBERT T.J., BUTLER W.E., et al.: Cervical spondylotic myelopathy surgical trial: Randomized, controlled trial design and rationale. Neurosurgery, 75: 33446, 2014.

8- HOLLY L.T., MATZ P.G., ANDERSON P.A., GROFF M.W., HEARY R.F., KAISER M.G., et al.: Clinical prognostic indicators of surgical outcome in cervical spondylotic myelopathy. J. Neurosurg. Spine, 11: 112-8, 2009.

9- KADAЙKA Z., BEDNARÍK J., NOVOTNY' O., URBÁNEK I. and DU SEK L.: Cervical spondylotic myelopathy: Conservative versus surgical treatment after 10 years. Eur. Spine J., 20: 1533-8, 2011.

10-KARADIMAS S.K., ERWIN W.M., ELY C.G., DETTORI J.R. and FEH $_{\text {LINGS M.G.: Pathophysiology and natural }}$ history of cervical spondylotic myelopathy. Spine (Phila Pa 1976) 38: (22 Suppl) 1S21-S36, 2013.

11- KARIKARI I.O., JAIN D., OWENS T.R., GOTTFRIED O., HODGES T.R., NIMJEE M., et al.: Impact of subsidence on clinical outcomes and radiographic fusion rates in anterior cervical discectomy and fusion: A systematic review. J. Spinal. Disord. Tech., 27: 1-10, 2014.

12- KWON S.Y., SHIN J.J., LEE J.H. and CHO W.H.: Prognostic factors for surgical outcome in spinal cord injury associated with ossification of the posterior longitudinal ligament (OPLL). J. Orthop. Surg., 10: 94, 2015.

13- MATZ P.G., ANDERSON P.A., HOLLY L.T., GROFF M.W., HEARY R.F., KAISER M.G., et al.: The natural history of cervical spondylotic myelopathy. J. Neurosurg. Spine, 11: 104-11, 2009L.

14- MATZ P.G., HOLLY L.T., MUMMANENI P.V., ANDERSON P.A., GROFF M.W., HEARY R.F., et al.: Anterior cervical surgery for the treatment of cervical degenerative myelopathy. J. Neurosurg. Spine, 11: 170-3, 2009 Link.

15- MUMMANENI P.V., KAISER M.G., MATZ P.G., ANDERSON P.A., GROFF M.W., HEARY R.F., et al.: Cervical surgical techniques for the treatment of cervical spondylotic myelopathy. J. Neurosurg. Spine, 11: 13041, 2009.

16- ROWLAND L.P.: Surgical treatment of cervical spondylotic myelopathy: Time for a controlled trial. Neurology, 42: 5-13, 1992.

17- SAMPATH P., BENDEBBA M., DAVIS J.D. and DUCKER T.B.: Outcome of patients treated for cervical myelopathy. A prospective, multicenter study with independent clinical review. Spine (Phila Pa 1976), 25: 670-6, 2000.

18- SENGUPTA D.K., KIROLLOS R., FINDLAY G.F. and SMITH E.T.: The value of MR imaging in differentiating between hard and soft cervical disc disease: A comparison with intraoperative findings Eur. Spine J., 8: 199-204, 1999.

19- YUE W.M., BRODNER W. and HIGHLAND T.R.: Longterm results after anterior cervical discectomy and fusion with allograft and plating: A 5- to 11-yearradiologic and clinical follow-up study. Spine (Phila Pa 1976), 30: 213844, 2005. 


\section{الجراحة الآمامية للغضروف العنقى الصلب واللين}

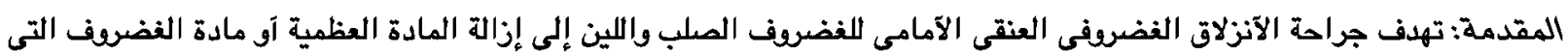

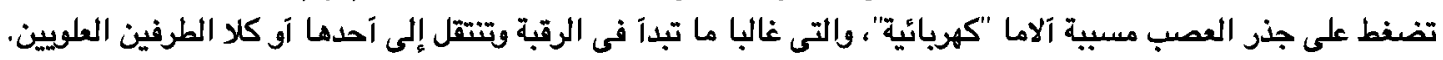

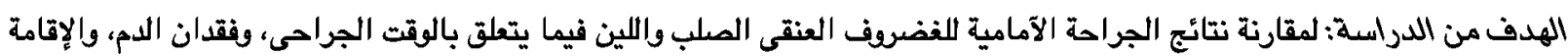

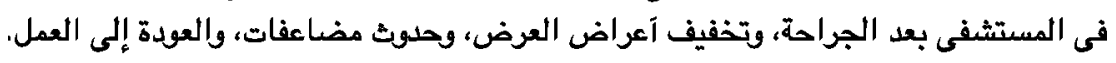

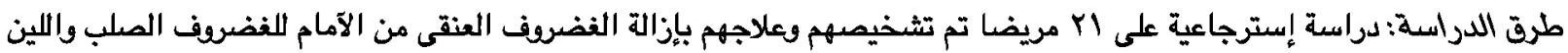

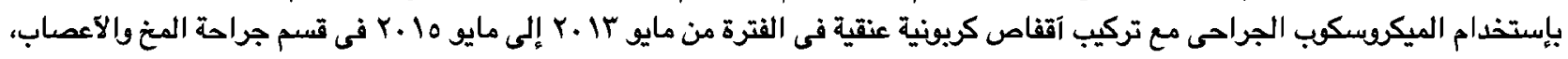
جامعة بنى سويف. تم تقسيم المرضى إلى مجموعتين:

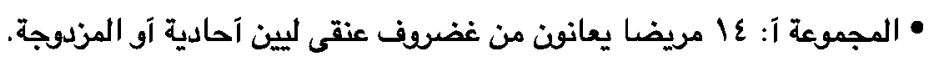
• المجموعة الثانية: V مرضى يعانون من غضروف عنق عنقى صلب آحادية آو مزدوجة.

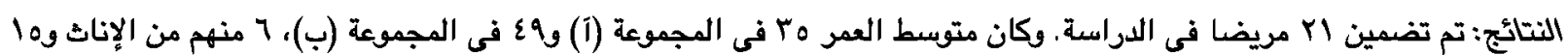

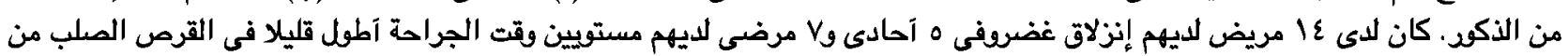

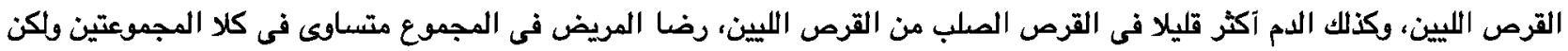

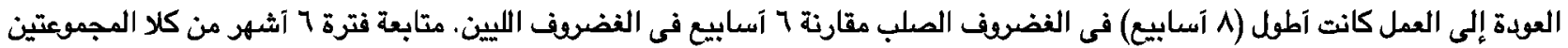
لا تظهر آى تغير فى النتيجة.

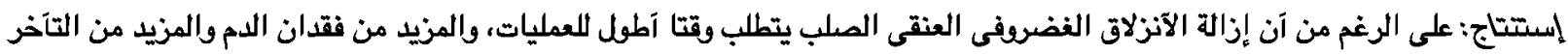

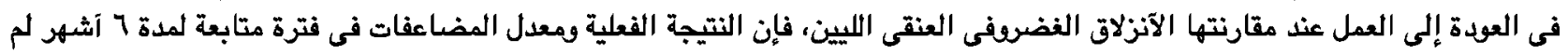
تختلف بين المجموعتين. 